\title{
SALAT GAIB UNTUK KORBAN BENCANA ALAM DALAM PERSPEKTIF HUKUM ISLAM
}

\author{
Saifullah bin Anshor \\ Sekolah Tinggi Ilmu Islam dan Bahasa Arab (STIBA) Makassar \\ saifullahanshar85@gmail.com \\ Rachmat bin Badani Tempo \\ Sekolah Tinggi Ilmu Islam dan Bahasa Arab (STIBA) Makassar \\ rachmatbadani16@gmail.com \\ Asri \\ Sekolah Tinggi Ilmu Islam dan Bahasa Arab (STIBA) Makassar \\ asridaeng1@gmail.com
}

\begin{abstract}
Keywords :
ABSTRACT

Pray, Gaib, Corpse, Disaster This study aimed at elaborating and identifying the law and the virtues of funeral prayer, the definition of absentee funeral prayer, the propositions of the inquiry of absentee funeral prayer, scholars' opinions on the law of absentee funeral prayer, the ruling of absentee funeral prayer, time and distance limit in absentee funeral prayer, and the law of absentee funeral prayer on the victims of natural disasters. This study employed qualitative-descriptive method with normative approach techniques and library research. The result of the study shows that: (1) The law of absentee funeral prayer is permissible on the corpse that is not yet prayed on; (2) The ruling of absentee funeral prayer is the same as the ruling of funeral prayer; (3) There is no time limit for performing absentee funeral prayer on condition that the person dies at the time person who wants to perform prayer has been able to perform prayer; (4) The distance limit of absentee funeral prayer is the distance in which it is difficult to be visited by people who want to perform prayer; (5) The natural disaster victim, if his or her body is not found and is not yet prayed on, then he/she can be prayed on in absentia.
\end{abstract}

\begin{tabular}{ll}
\hline Kata kunci : & \multicolumn{1}{c}{ ABSTRAK } \\
\cline { 2 - 3 } Salat, Gaib, Jenazah, Bencana & Penelitian ini bertujuan untuk membahas dan mengkaji hukum dan \\
& keutamaan salat jenazah, definisi salat gaib, dalil disyariatkannya \\
& salat gaib, pendapat ulama terhadap hukum salat gaib, tata cara salat \\
gaib, batasan waktu dan jarak dalam salat gaib, dan hukum salat \\
gaib untuk korban bencana alam. Penelitian ini menggunakan \\
metode kualitatif-deskriptif dengan teknik pendekatan normatif dan \\
library research. Hasil penelitian menunjukkan bahwa: (1) Hukum \\
salat gaib boleh dilakukan untuk jenazah yang belum disalati; (2) \\
Tata cara salat gaib sama dengan pelaksanaan salat jenazah; (3) \\
Tidak ada batas waktu untuk pelaksanaan salat gaib dengan syarat \\
si mayit meninggal pada masa orang yang ingin menyalatkannya \\
secara gaib sudah bisa melaksanakan salat; (4) Batas jarak bolehnya \\
\hline
\end{tabular}


BUSTANUL FUQAHA: Jurnal Bidang Hukum Islam

Vol. 1, No. 3 (2020) : Hal. 311-329

Website: https://journal.stiba.ac.id

salat gaib apabila tempat jenazah sulit untuk didatangi oleh orang yang ingin menyalatinya; (5) Jenazah korban bencana alam jika tidak ditemukan jasadnya dan belum disalati maka boleh disalati secara gaib. 
BUSTANUL FUQAHA: Jurnal Bidang Hukum Islam

Vol. $X X$, No. $X(X X X X)$ : Hal.

Website: https://journal.stiba.ac.id

ISSN: (Online) (Printed)

\section{PENDAHULUAN}

Setiap manusia dan makhluk bernyawa lainnya akan mengalami kematian, dan ini adalah suatu kepastian yang tidak ada yang bisa menghindar darinya. Namun, terdapat tiga rahasia kematian yang tak seorang pun mengetahuinya, yaitu kapan ia meninggal, di mana ia meninggal, dan bagaimana kematian itu datang. Ada yang meninggal karena umur yang sudah tua, ada yang disebabkan oleh kecelakaan, ada yang karena tertimpa reruntuhan dan bencana alam, bahkan ada yang meninggal tanpa sebab. Bagi manusia yang masih hidup dan mendapati saudaranya meninggal dunia maka ia berkewajiban untuk menyelengarakan jenazahnya dengan cara yang sudah ditetapkan dalam syariat Islam.

Di antara proses penyelenggaraan jenazah adalah menyalatkannya, dengan menghadirkan jenazah tersebut di hadapan imam beserta jemaah yang akan ikut menyalatkan jenazahnya. Hukum melaksanakan salat jenazah adalah fardu kifayah, yang apabila sebagian kaum muslimin telah melaksanakannya, maka gugurlah kewajiban kaum muslimin lainnya, dan jika tidak ada yang melakukannya, maka seluruh kaum muslimin berdosa akibat meninggalkan kewajiban tersebut. Imam Nawawi rahimahullah menyebutkan:

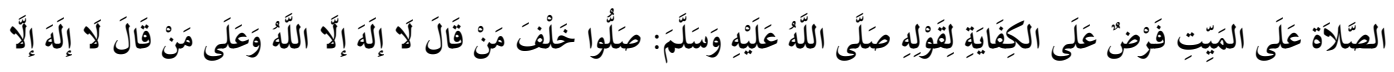

Artinya: "Salat jenazah hukumnya fardhu kifayah berdasarkan sabda Rasulullah saw.: Salatlah di belakang orang yang mengucapkan kalimat Laa Ilaha Illallah, dan salatlah untuk orang yang mengucapkan kalimat Laa Ilaha Illallah."1

Namun, di antara hal yang terkadang terjadi di luar dugaan dan kebiasaan manusia adalah apabila ada dari kaum muslimin yang meninggal dunia dan tidak berada di tempat ketika akan disalatkan. Hal itu disebabkan oleh kondisi umat Islam yang sedang tertimpa bencana alam dan jenazahnya sulit untuk ditemukan, semisal tertimbun tanah longsor, terbawa arus tsunami atau banjir bandang, terjerembab ke dalam tanah akibat likuefaksi, dan yang lainnya. Dengan kondisi demikian, maka tidak memungkinkan lagi untuk digali, dicari-temukan dan diselenggarakan jenazahnya sebagaimana lazimnya. Peristiwa seperti ini pernah terjadi di Palu (Sulawesi Tengah) dengan bencana alam berupa gempa bumi, tsunami dan likuefaksi. ${ }^{2}$ Demikian juga baru-baru ini, terjadi di Masamba (Sulawesi Selatan) dengan banjir bandang berserta lumpur yang mengeras dan

1 Yahya bin Syaraf Al-Nawāwi, al-Majmu', Juz V (Beirut: Dār al-Fikr,1997), h. 211 27 Juli 2020)

${ }^{2}$ https://fajar.co.id/2019/07/02/bahaya-korban-gempa-palu-diminta-tinggalkan-zona-merah/, (Diakses tanggal

Saifullah bin Anshor, Rachmat Badani bin Tempo, Asri. Salat Gaib Untuk ... 
menenggelamkan rumah-rumah warga. $^{3}$ Atas peristiwa-peristiwa tersebut, terdapat fakta bahwa korban bencana alam dari kaum muslimin, atau jenazahnya sulit untuk dicari dan ditemukan.

Dengan demikian, timbul pertanyaan apakah syariat Islam membolehkan pelaksanaan salat gaib untuk jenazah tersebut? yakni pelaksanakan salat jenazah sementara jenazah tidak berada di tempat, khususnya setelah wafatnya Rasulullah saw.

Berangkat dari permasalahan di atas, maka penting untuk mengkaji bagaimana syariat Islam mendudukkan permasalahan ini, terlebih lagi di zaman yang semakin banyaknya bencana-bencana alam yang menimpa kaum muslimin, sehingga semakin besar kebutuhan mereka untuk mengetahui hukum penyelenggaraan salat gaib untuk jenazah yang tertimpa bencana alam tersebut.

Permasalahan yang kemudian urgen untuk dijawab dalam penelitian ini adalah:

1. Bagaimana hukum salat gaib setelah wafatnya Rasulullah saw.?;

2. Bagaimana tata cara salat gaib dan berapa batasan waktu serta jarak dalam salat gaib?;

3. Bagaimana hukum salat gaib untuk korban bencana alam dalam perspektif hukum Islam?.

Oleh karena itu, penelitian ini dilakukan dengan tujuan untuk membahas dan mengkaji hukum salat gaib setelah wafatnya Rasulullah saw., tata cara salat gaib dan berapa batasan waktu serta jarak dalam salat gaib, dan hukum salat gaib untuk korban bencana alam.

Penelitian ini merupakan penelitian kualitatif-deskriptif dengan teknik pendekatan normatif dan library research (riset kepustakaan). Pendekatan normatif adalah sebuah pendekatan untuk mengetahui nilai-nilai kebenaran yang menjadi obyek penelitian. ${ }^{4}$ Adapun teknik library research pada penelitian ini, maka menggunakan jenis data primer yang diperoleh dari Al-Qur'an, hadis Rasulullah saw. dan ijmak para ulama muktabar.

Selain itu, teknik ini juga menggunakan data sekunder yang diperoleh dari penjelasan para ulama mengenai kandungan ayat-ayat Al-Qur'an dan hadis Rasulullah saw. yang terhimpun dalam bentuk buku, majalah, jurnal, atau artikel ilmiah. Adapun beberapa penelitian terdahulu yang pernah dilakukan berkaitan dengan permasalahan penelitian ini dan menjadi referensi penelitian, di antaranya yaitu:

Kitab Aḥkām al-Janāiz karya Syaikh Nasiruddīn al-Albāni. Kitab ini berisi penjelasan mengenai hukum-hukum seputar penyelenggaraan jenazah, di

${ }^{3}$ https://makassar.tribunnews.com/2020/07/14/fakta-fakta-terbaru-banjir-bandang-terjang-masamba-lutra-inijalur-alternatif-agar-tidak-terjebak?page=1, (Diakses tanggal 27 Juli 2020).

${ }^{4}$ Abuddin Nata, Metode Studi Islam (Jakarta: Raja Grafindo Persada, 2002), h. 28. 
BUSTANUL FUQAHA: Jurnal Bidang Hukum Islam

Vol. 1, No. 3 (2020) : Hal. 311-329

Website: https://journal.stiba.ac.id

antaranya adalah salat terhadap jenazah yang memiliki korelasi dengan salah satu pembahasan dalam penelitian ini.

Kitab Aḥkām al-Janāiz karya Sā̄d bin 'Ali bin Wahf Al-Qahṭani. Kitab ini berisi penjelasan mengenai hukum-hukum penyelenggaraan jenazah, di antaranya adalah penjelasan salat gaib dan keadaan-keadaan dibolehkannya pelaksanaan salat gaib.

Kitab Salat Gaib karya Hisām Al-Din bin Mūsa Muhammad bin 'Afanah. Kitab ini berisi penjelasan mengenai dalil-dalil pelaksanaan salat gaib, perbedaan ulama mengenai syariat salat gaib, serta beberapa masalah terkait tentangnya. Kitab ini sangat relevan untuk menjadi salah satu referensi penelitian karena penulis telah mengumpulkan dalil-dalil salat gaib hingga beberapa persoalan tentang salat gaib, salah satunya hukum salat gaib untuk jenazah dalam jumlah banyak. Namun, penulis kitab ini tidak membahasnya secara ilmiah dan terperinci, melainkan sekadar bersifat argumen semata pada akhir pembahasannya.

Dengan demikian, dalam penelitian ini, kebaruannya terletak pada isi pembahasan dan telaah yang lebih lengkap pada persoalan hukum salat gaib, batasan waktu dan jarak dalam salat gaib, dan secara khusus pembahasan mengenai hukum salat gaib untuk korban bencana alam, yang tidak ditemukan pada penelitian-penelitian sebelumnya.

\section{PEMBAHASAN}

\section{Hukum dan Keutamaan Salat Jenazah}

Mayoritas ulama fikih berpendapat bahwa salat jenazah hukumnya adalah fardu kifayah, yang apabila sebagian kaum muslimin sudah melakukannya, maka gugurlah kewajiban kaum muslimin lainnya, namun, jika tidak ada yang melakukannya, maka seluruh kaum muslimin berdosa. Imam Nawawi rahimahullah menukilkan bahwa ulama telah berijmak akan hal ini. ${ }^{5}$ Akan tetapi sebagian ulama Malikiyyah berpendapat bahwa salat jenazah hukumnya sunah dan bukan fardu. ${ }^{6}$

Keutaman salat jenazah dan anjuran untuk melaksanakannya disebutkan dalam beberapa hadis di antaranya:

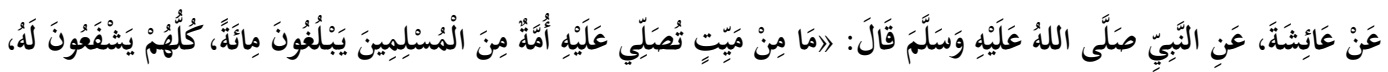

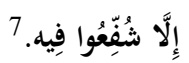

${ }^{5}$ Yahya bin Syaraf Al-Nawāwi, al-Majmu', Juz V (Beirut: Dār al-Fikr,1997), h. 212. 456.

${ }^{6}$ Syihābuddin Ahmmad bin Idrīs al-Qarrāfi, al-Żakhirah, Juz II (Cet. I; Beirut: Dār al-Garb Al-Islamy, 1994), h.

\footnotetext{
${ }^{7}$ Muslim bin Hajjāj, Șahih Muslim, Juz II (Beirut: Dār Ihya Turaś Arabi), h. 654.
} 
BUSTANUL FUQAHA: Jurnal Bidang Hukum Islam

Vol. 1, No. 3 (2020) : Hal. 311-329

Website: https://journal.stiba.ac.id

Artinya: "Dari 'Āisyah raḍiyallahu 'anhā dari Nabi saw. bahwasanya beliau bersabda: "Tidaklah seseorang meninggal dunia kemudian disalatkan jenazahnya oleh seratus muslim dan semuanya memberikan syafaat kecuali jenazah tersebut akan mendapatkan syafaat."

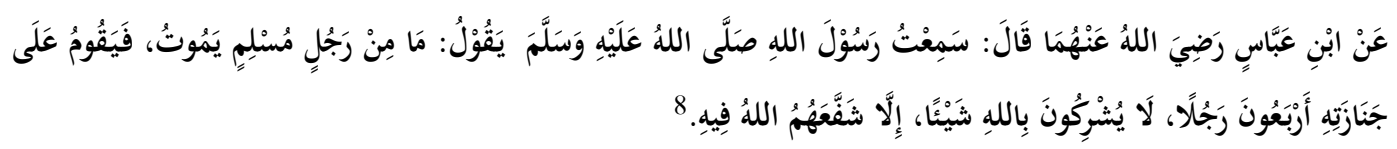

Artinya: "Dari 'Abdullāh bin 'Abbās raḍiyallahu 'anhu beliau berkata; saya mendengar Rasulullah saw. bersabda: "Tidaklah seorang muslim meninggal dunia kemudian disalatkan jenazahnya oleh empat puluh orang yang tidak menyekutukan Allah dengan sesuatu pun kecuali jenazah tersebut akan mendapatkan syafaat dari Allah.”

\section{Definisi Salat Gaib}

Secara etimologi salat berasal dari bahasa Arab صلّى-يصلّى yang bermakna doa. ${ }^{9}$ Secara terminologi salat adalah ibadah kepada Allah yang meliputi perkataan, perbuatan, gerakan khusus yang dimulai dengan takbir dan diakhiri dengan salam. ${ }^{10}$

Adapun gaib bermakna tidak hadir, sembunyi, tenggelam. ${ }^{11}$ Jadi, yang dimaksud dengan salat gaib adalah menyalatkan jenazah yang tidak berada di tempat atau berada di negeri lain.

\section{Dalil Disyariatkannya Salat Gaib}

Seyogianya salat jenazah dilakukan dengan menghadirkan jenazah di hadapan imam dan orang yang akan menyalatkannya, namun, terkadang pada keadaan tertentu tidak memungkinkan untuk menghadirkan jenazah tersebut, maka apakah boleh melaksanakannya tanpa kehadiran jenazah di tempat?.

Mengenai pensyariatan salat gaib, maka terdapat perselisihan di antara para ulama. Hal ini berangkat dari beberapa hadis yang berkaitan dengan salat gaib yang dengannya para ulama menjadikan dalil terhadap pendapat mereka masingmasing. Dijelaskan dalam beberapa riwayat bahwa Rasulullah saw. pernah melakukan salat gaib terhadap beberapa orang sahabatnya atau kaum muslimin yang meninggal. Di antara sahabat yang disalatkan oleh Rasulullah saw. dan jenazah mereka tidak bersama Rasulullah saw. yaitu:

\footnotetext{
${ }^{8}$ Muslim bin Hajjāj, Șahih Muslim, Juz II, h. 655.

${ }^{9}$ Muhammad bin Ya'kub al-Fairuzabadi, al-Qāmus al-Muhith(Cet. VIII; Beirut: Muassasah al-Risalah, 2005) h. 1304.

${ }^{10}$ Ibrāhīm bin Muhammad bin 'Abdullah bin Muhammad bin Muflih, al-Mubdi' Fii Syarhil Muqni'. Juz I (Cet. I; Beirut: Dār al-Kutub al-Ilmiyah, 1997) h. 263.

${ }^{11}$ Muhammad bin Ya'kub al-Fairuzabadi, al-Qamus al-Muhith, h. 121.
} 
BUSTANUL FUQAHA: Jurnal Bidang Hukum Islam

Vol. 1, No. 3 (2020) : Hal. 311-329

Website: https://journal.stiba.ac.id

1. Najasyi (Raja Habasyah) radiyallahu 'anhu.

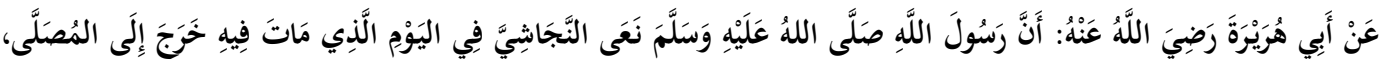

$$
\begin{aligned}
& \text { فَصَفَّ بِهِمْ وَكَبَّرَ أَرْبَعَا. } 12
\end{aligned}
$$

Artinya: "Dari Abū Hurairah radiyallahu 'anhu berkata: bahwasanya Rasulullah saw. pernah mengumumkan atas kematian Najasyi di hari kematiannya, dan Rasulullah saw. mengajak para sahabat untuk keluar ke lapangan dan membuat saf lalu beliau bertakbir empat kali (salat gaib)."

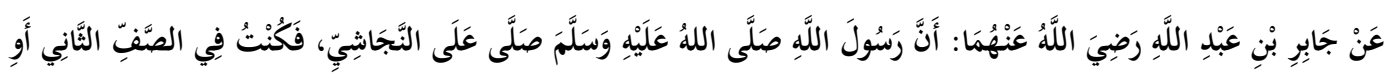

Artinya: "Dari Jābir bin 'Abdullah rạ̣iyallahu 'anhu berkata: bahwasanya Rasulullah saw. pernah melakukan salat gaib terhadap jenazah Najasyi, dan saya berada pada saf kedua atau ketiga."

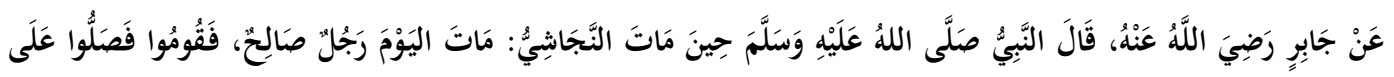
أَخِيكُمْ أَصْحَمَنَة. 14

Artinya: "Dari Jābir raḍiyallahu 'anhu bahwasanya Rasulullah saw. pernah bersabda di hari kematian najasyi: "Hari ini telah meninggal dunia orang yang saleh, maka berbaris dan salatlah (salat gaib) atas saudara kalian aṣhamah.”

Dan masih banyak hadis-hadis yang menjelaskan bahwa Rasulullah saw. melakukan salat gaib terhadap jenazah Najasyi.

2. Mu'āwiyah bin Mu'āwiyah al-Lais̀ī atau al-Muzani raḍiyallahu 'anhu.

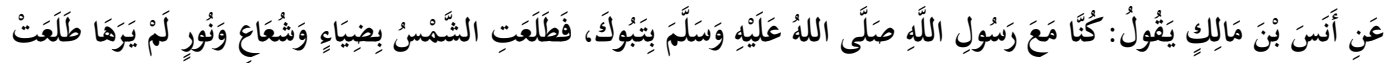

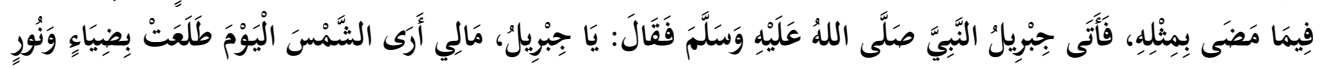

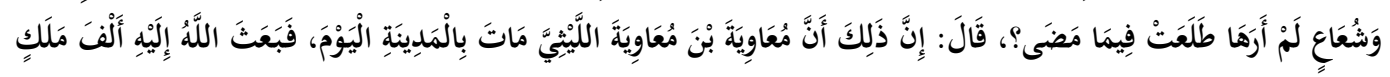

\footnotetext{
${ }^{12}$ Muhammad bin Ismail al-Bukhāri, Sahih al-Bukhari, Juz II (Cet. I; Dār Tuq an-Najah, 1422 H), h. 72.

${ }^{13}$ Muhammad bin Ismail al-Bukhāri, Sahih al-Bukhari, Juz II, h. 86.

${ }^{14}$ Muhammad bin Ismail al-Bukhāri, Sahih al-Bukhari, Juz V, h. 51.
} 


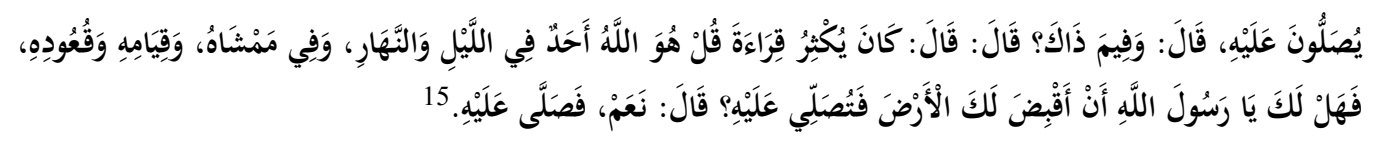

Artinya: "Dari Anas bin Mālik raḍiyallahu 'anhu berkata: bahwa dulu kami pernah bersama Rasulullah saw. di Tabuk, pada hari itu matahari terbit dengan cahaya dan sinar yang terang yang tidak pernah terbit seperti itu sebelumnya, malaikat Jibril pun datang kepada Rasulullah, dan Rasulullah bertanya: wahai Jibril apa yang terjadi kenapa matahari hari ini terbit dengan cahaya yang berbeda dengan harihari sebelumnya?, aku tidak pernah melihat seperti ini sebelumnya?, Malaikat Jibril pun menjawab: hal itu terjadi disebabkan karena Mu'āwiyah bin Mu'āwiyah al-Lais̀ī telah meninggal dunia hari ini di Madinah, dan Allah Ta'ala telah mengutus seribu malaikat untuk mensalatinya, Rasulullah pun bertanya: kenapa hal itu bisa terjadi?, Malaikat Jibril menjawab: karena Muawiyah semasa hidupnya sering membaca surah al-Ikhlash di siang ataupun di malam hari, berjalan, duduk, ataupun berdiri, maukah engkau wahai Rasulullah aku ambilkan tempat untuk mensalatkannya? Rasulullah menjawab: Iya, maka beliaupun menyalatkannya (salat gaib)."

Beberapa riwayat lainnya juga menerangkan hal yang sama bahwa Rasulullah saw. mensalatkan jenazah Mu'āwiyah bin Mu'āwiyah al-Lais̀i di Madinah sementara beliau berada di Tabuk, namun, semua riwayat tentang hal ini dilemahkan oleh para ulama hadis disebabkan perawinya yang lemah dan meriwayatkan hadis munkar sebagaimana yang disebutkan oleh Imam Baihaqi setelah meriwayatkan hadis di atas. ${ }^{16}$

Al-Wāqidī juga menyebutkan dalam kitabnya Al-Magāzy: bahwasanya Rasulullah saw. juga pernah mensalatkan jenazah Zaid bin Ḥāritsah dan Ja'far bin Abi Tholib raḍiyallahu 'anhumā setelah keduanya syahid di perang mu'tah, sebagaimana hal ini disebutkan oleh Zayla' $i^{17}$ dan lainnya. Namun, hadis-hadis yang berkaitan dengan salat gaib Rasulullah saw. terhadap Zaid dan Ja'far yang dinukilkan oleh Al-Wāqidī tidak lepas dari kritikan para ulama hadis, karena AlWāqidī dalam periwayatan hadis yang beliau sebutkan sanadnya adalah lemah, apalagi jika tidak disebutkan sanadnya, ${ }^{18}$ dan juga makna salat yang disebutkan dalam riwayatnya bukan bermakna salat sebagaimana yang dipahami tapi yang dimaksudkan adalah doa.

\footnotetext{
${ }^{15}$ Abu Bakar Ahmad bin Husain al-Baihaqi, Sunan al-Kubra, Juz VII (Cet. I; Markaz Hajr li al-Buhuts wa alDirasat al-Arabiah wa al-Islamiyah, 2011), h. 428. Hadis ini dilemahkan oleh Syaikh Albani dalam kitab Silsilah Al-Ahadits Al-Daifah wa Al-Mauduah (Cet. I; Al-Madinah Al-Munawwarah: Maktabah Al-Ulum wa Al-Hikam, 1431H/2010M), h. 438 .

${ }^{16}$ Abu Bakar Ahmad bin Husain al-Baihaqi, Sunan al-Kubra, Juz VII, h. 428 H), h. 205.

${ }^{17}$ Abdullah bin Yusuf al-Zayla'I, Nashbu al-Rāyah li Ahādist al-Hidayah, Juz II (Mesir: Dār al- Hadits, 1357 Ilmiyah), h. 323
} 
Setelah pemaparan riwayat-riwayat yang berkaitan dengan salat gaib, maka tampak jelas bahwa yang sahih dalam hal ini hanyalah hadis tentang salat gaib yang dilakukan oleh Rasulullah saw. terhadap jenazah Najasyi. Adapun riwayat tentang sahabat lainnya, maka tidaklah sahih sehingga tidak bisa dijadikan landasan dalam menetapkan hukum sebagaimana yang telah dijelaskan oleh para ulama hadis. ${ }^{19}$

\section{Pendapat Ulama Terhadap Hukum Salat Gaib}

Mengenai pensyariatan salat gaib, para ulama berbeda pendapat, ada yang menyebutkan perbedaan tersebut terbagi menjadi dua pendapat, sebagian yang lain menyebutkan tiga dan yang lainnya menyebutkan empat, namun, jika dicermati lebih detail pendapat para ulama, maka akan didapati ada enam pendapat, dan semua pendapat tersebut tidak lepas dari perbedaan pemahaman terhadap hadis salat gaib yang dilakukan oleh Rasulullah saw. kepada Najasyi yang telah disebutkan sebelumnya. Apakah hadis tersebut umum dan berlaku setelah wafatnya Rasulullah atau khusus untuk Rasulullah kepada Najasy saja?.

Selain hal tersebut, para ulama yang memahami bahwa salat gaib tetap disyariatkan setelah wafatnya Rasulullah saw. juga berbeda pendapat tentang kriteria jenazah yang boleh disalatkan secara gaib, apakah karena jenazah Najasy belum disalatkan sebelumnya ataukah karena Najasyi adalah orang saleh yang banyak memberikan manfaat kepada Islam dan kaum muslimin? atau karena letak geografis Habasyah yang berada di arah kiblat atau sejajar dengannya, atau karena ada sebab yang lain?. Berikut ini adalah pendapat para ulama serta dalil-dalil yang dijadikan sebagai dasar argumen mereka:

Pendapat Pertama. Salat gaib tidak disyariatkan secara mutlak setelah wafatnya Rasulullah saw., ini adalah pendapat Hanafiyyah, ${ }^{20}$ Malikiyyah, ${ }^{21}$ dan juga salah satu riwayat dari Imam Ahmad.22 Akan tetapi di kalangan Malikiyah terdapat perbedaan di antara mereka, sebagian berpendapat makruh dan sebagian lainnya berpendapat haram. Adapun dalil yang digunakan oleh pendapat ini adalah sebagai berikut:

1. Karena salat gaib adalah amalan khusus bagi Rasulullah saw. untuk Najasy.

2. Begitu banyak para sahabat yang meninggal dunia di tempat yang jauh dari Madinah di masa Rasulullah saw. masih hidup, terutama dari kalangan para

\footnotetext{
${ }^{19}$ Syamsuddin Abu Abdillah al-Zahabi, Siyar A 'lam Nubala', Juz III, (Mesir: Dār al-Hadis, 2006), h. 260.

${ }^{20}$ Abdurrahman bin Muhammad al-Kalibuli, Majma' al-Anhar fi Syarhi Multaqa al-Abhar, Juz I, (Beirut. Dār alKutub al-Ilmiyyah, 1998), h. 272.

${ }^{21}$ Syihabuddin Ahmad bin Idris al-Qarrafi, al-Zakhirah. Juz II, h. 468.

${ }^{22} \mathrm{Abu}$ Muhammad Muwaffaq al-Din Abdullah bin Ahmad bin Muhammad bin Quddamah, al-Mugni, Juz II, (Maktabah al-Qahirah, 1968). h. 382.
} 
BUSTANUL FUQAHA: Jurnal Bidang Hukum Islam

Vol. 1, No. 3 (2020) : Hal. 311-329

Website: https://journal.stiba.ac.id

penghafal Al-Qur'an yang mana mereka adalah sebaik-baik manusia namun, tidak ada satupun riwayat sahih yang menjelaskan bahwa Rasulullah saw. melakukan salat gaib untuk mereka, padahal beliau sangat gemar melakukan kebaikan untuk sahabatnya, sebagaimana diriwayatkan:

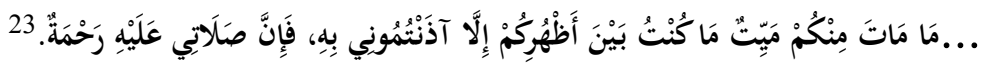

Artinya: "Janganlah ada yang meninggal di antara kalian dan saya masih berada di tengah-tengah kalian kecuali kalian memberitahukan kepadaku atas kematiannya, karena sesungguhnya salat jenazah yang kulakukan untuknya akan menjadi rahmat baginya."

3. Salat gaib tidak pernah dilakukan setelah wafatnya Rasulullah saw. dan tidak ada satupun dari kalangan kaum muslimin yang melakukannya terhadap jenazah Rasulullah saw. setelah beliau wafat. ${ }^{24}$

4. Di antara syarat salat jenazah adalah dihadirkannnya jenazah tersebut di hadapan imam dan makmum, karena jika ada jenazah di satu daerah, maka tidak boleh disalatkan jika tidak berada dihadapan imam. ${ }^{25}$

Pendapat Kedua. Salat gaib disyariatkan secara mutlak, ini adalah pendapat Syafi'iyyah ${ }^{26}$ dan Hanabilah, ${ }^{27}$ dan juga pendapat yang dipilih oleh Ibnu Hazm dalam kitabnya Al-Muh alla. Ibnu Hazm berkata :

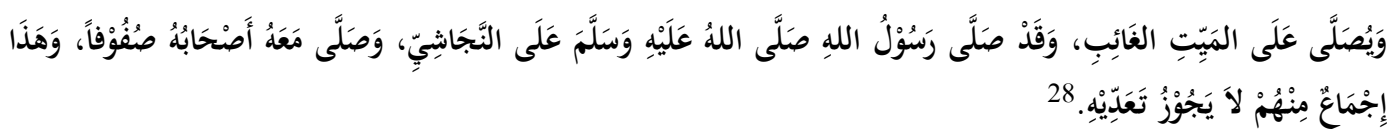

Artinya: "Dan boleh melaksanakan salat gaib, sebagaimana Rasulullah saw. pernah salat gaib terhadap jenazah Najasy, dan para sahabat juga ikut serta dalam salat tersebut yang tergabung pada beberapa barisan, dan ini merupakan ijmak dari para sahabat, sehingga tidak boleh menyelisihinya."

Adapun dalil yang digunakan pendapat ini adalah sebagai berikut:

\footnotetext{
${ }^{23}$ Muhammad bin Hibban bin Ahmad al-Tamimi, Sahih Ibnu Hibban Bitartib Ibnu Bilban, Juz VII, (Cet. II; Beirut: Muassasah al-Risalah, 1993), h. 356.

${ }^{24}$ Mahmud Muhammad Khatthab al-Subki, al-Din al-Khalis Aw Irsya al-Kholq Ila Din al-Haq (Cet. III; alMaktabah al-Mahmudiyyah al-Subkiyyah, 1980), h. 367. 382.

${ }^{25}$ Abu Muhammad Muwaffaq al-Din Abdullah bin Ahmad bin Muhammad bin Quddamah, al-Mugni. Juz II, h.

${ }^{26}$ Yahya bin Syaraf al-Nawawi, al-Majmu', Juz V, (Beirut: Dār al-Fikr,1997),.h 252.

${ }^{27}$ Mansur bin Yunus al-Bahuti al-Hanbali, Kassyaf al-Qonna' 'an Matan al-Iqna' Juz II, (Dār al-Kutub alIlmiyyah), h. 121

${ }^{28}$ Abu Muhammad Ali bin Ahmad bin Hazm al-Andalusi, al-Muhalla, Juz V (Beirut: Dār al-Fikr), h. 169.
} 
1. Hadis tentang salat gaib yang dilakukan oleh Rasulullah saw. terhadap jenazah Najasyi yang telah disebutkan sebelumnya. Adapun hadis tersebut adalah hadis yang sahih, sehingga amalan tersebut disyariatkan selama tidak ada dalil yang menghapusnya atau mengkhususkannya hanya untuk Rasulullah saw., dan tidak ada satu riwayatpun yang menjelaskan hal itu.

2. Inti dari salat jenazah adalah doa, dan orang yang didoakan tidak dipersyaratkan untuk hadir. Imam Syafi'i mengatakan:

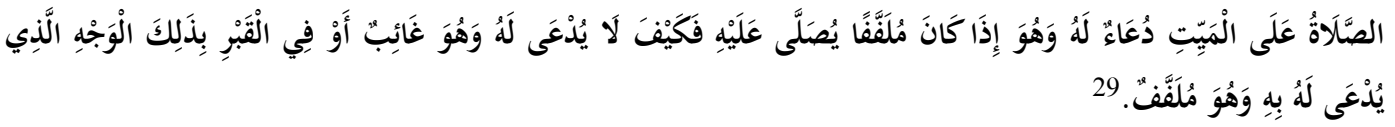

Artinya: "Salat jenazah adalah merupakan doa untuk si mayit, dan apabila telah dikafani, maka disalatkan, lalu apa yang menghalangi seseorang untuk tidak mendoakannya secara gaib padahal sudah dikafani dan sudah dikubur?."

3. Sebagaimana disebutkan oleh Ibnu Hazm bahwa tidak ada riwayat dari sahabat yang melarang hal tersebut, ${ }^{30}$ ini menunjukkan bahwa salat gaib disyariatkan sepanjang masa.

Pendapat Ketiga. Salat gaib disyariatkan untuk jenazah yang berada di sebuah daerah yang mana jenazah tersebut belum disalatkan di daerah tersebut, atau diperkirakan jenazahnya belum disalatkan. Pendapat ini dipilih oleh Abu Daud, ${ }^{31}$ al-Khatthabi, ${ }^{32}$ Syaikhul Islam Ibnu Taimiyyah, ${ }^{33}$ Ibnul Qoyyim al-Jauziyyah, ${ }^{34}$ dan juga merupakan salah satu pendapat dalam mazhab Imam Ahmad. ${ }^{35}$ Adapun dalil yang digunakan pendapat ini adalah sebagai berikut:

1. Ketika para Khulafaurrasyidin dan juga sahabat lainnya meninggal dunia tidak ada satupun dari kaum muslimin yang melaksanakan salat gaib untuk mereka, dan seandainya mereka melakukannya, maka telah sampai riwayat tentang hal tersebut. ${ }^{36}$ Adapun salat gaib yang dilakukan Rasulullah saw. terhadap 1379), h. 188

${ }^{29}$ Ahmad bin Ali bin Hajar al-Asqalani, Fath al-Bāri Syarh Sahih al-Bukhāri, Juz III, (Beirut: Dār al-Ma'rifah,

${ }^{30}$ Abu Muhammad Ali bin Ahmad bin Hazm al-Andalusi, al-Muhallā, Juz V, h. 139.

${ }^{31}$ Muhammad Syamsul Haq al-Adzim Aabaadi, 'Aun al-Ma'bud Syarh Sunan Abi Daud Juz XI, (Cet. II; Beirut, Dār al-Kutub al-Ilmiyah 1415 H), h. 5.

${ }^{32}$ Hamd bin Muhammad bin Ibrahim Al-Khatthabi, Ma'alim Al-Sunan, Juz I (Cet. I; Halb: Al-Matba'ah Al'Ilmiyyah, 1351H/1932M), h. 310-311.

${ }^{33}$ Taqiyuddin Abul Abbas Ahmad bin Abdul Halim Ibnu Taimiyyah, al-Mustadrak 'ala Majmu' al-Fatawa, Juz III (Cet. I; 1418H), h. 144

${ }^{34}$ Muhammad bin Abi Bakar bin Ayyub Ibnul Qoyyim, Zād al-Ma'ād fi Hadyi Khairi al- 'Ibād(Cet. XIV; Beirut: Muassasah al-Risalah, 1986), h. 500

${ }^{35}$ Ali bin Sulaiman al-Mardaawi, al-Inshaf fii Ma'rifati al-Rajih min al-Khilaf ala Mazhab Imam Ahmad bin Hanbal, Juz II (Beirut: Dār Ihya al-Turats al-Araby), h. 533.

${ }^{36}$ Muhammad Nasiruddin al-Albani, Ahkam Janaaiz wa Bida 'iha (Cet. IV; Beirut: al-Maktabah al-Islami, 1986), h. 111-112. 
jenazah Najasyi, karena Najasyi meninggal di Negara syirik dan belum ada yang mensalatkan jenazahnya.

2. Salat jenazah hukumnya adalah fardu kifayah, maka selama ada jenazah muslim yang belum disalatkan karena suatu uzur, maka boleh dilakukan salat gaib untuk jenazah tersebut, agar kewajiban kaum muslimin lainnya gugur.

Pendapat Keempat. Salat gaib disyariatkan untuk orang yang banyak memberikan manfaat semasa hidupnya dalam agama, dengan harta, amalan, jihad, atau ilmunya. Pendapat ini dinukil dari Imam Ahmad sebagaimana yang disebutkan oleh Syaikul Islam Ibnu Taimiyah dalam fatwanya, ${ }^{37}$ dan dipilih oleh Syaikh 'Abdul 'Azīz bin Bāz, ${ }^{38}$ dan merupakan fatwa al-Lajnah al-Dāimah. ${ }^{39}$

Hal ini berdasarkan pemahaman bahwa Rasulullah saw. melakukan salat gaib terhadap jenazah Najasyi bukan karena belum ada yang mensalatkannya, karena tidak ada riwayat yang menerangkan hal tersebut, akan tetapi Rasulullah saw. melakukan salat gaib karena Najasyi adalah orang saleh yang telah banyak memberikan kontribusi kepada Islam dan kaum muslimin terutama saat hijrah ke Habasyah.

Pendapat Kelima. Salat gaib disyariatkan jika tempat meninggalnya berada di arah kiblat, pendapat ini hanya dinukil dari Ibnu Hibban, dan tidak ada ulama selainnya yang berpendapat demikian sebagaimana yang disebutkan oleh al-Imam alThabari. ${ }^{40}$ Hal ini berdasarkan pemahaman beliau bahwa letak geografis Habasyah berada di arah kiblat atau sejajar dengan kiblat, karena bagi yang bermukim di Madinah, letak Habasyah berada di antara Makkah dan Madinah, sehingga jika ada yang meninggal dunia dan tidak berada di arah kiblat, maka tidak boleh dilakukan salat gaib terhadap jenazah tersebut karena berlawanan dengan arah kiblat. ${ }^{41}$

Pendapat Keenam. Salat gaib disyariatkan hanya untuk jenazah yang meninggal hari itu atau yang belum lama meninggalnya. Adapun jika jenazahnya sudah lama meninggal, maka tidak disyariatkan salat gaib, sebagaimana diceritakan oleh Ibnu Abdil Barr dari sebagian ulama. ${ }^{42} \mathrm{Hal}$ ini berdasarkan bahwa ketika Rasulullah saw. mendapatkan kabar kematian Najasyi dari malaikat Jibril as., maka seketika

\footnotetext{
${ }^{37}$ Taqiyuddin Abul Abbas Ahmad bin Abdul Halim Ibnu Taimiyyah, al-Fatā wa al-Kabir, Juz V (Cet. I; Beirut: Dār al-kutub al-Ilmiyah, 1987), h. 360.

${ }^{38}$ Abdul Aziz bin Baz, Majmu’ Fatā wa, Juz XIII (t.t.; al-Riasah al-'ammah lilbuhuts al-ilmiyah walifta'), h. 158159.

${ }^{39}$ Ahmad bin Abdurrazzaq al-Duwaisy, fataawa lajnah al-daimah Lilbuhuts al-Ilmiyah Waliftaa', Juz VIII (Cet. al-Riasah al-'ammah lilbuhuts al-ilmiyah walifta'), h. 418.

${ }^{40}$ Ahmad bin Ali bin Hajar al-Asqalani, Fath al-Bāri Syarh Sahih al-Bukhari, Juz III (Beirut: Dar al-Ma'rifah, 1379H), h. 188

${ }^{41}$ Muhammad bin Hibban bin Ahmad al-Tamimi, Shahih Ibnu Hibban Bitartibi Ibnu Bilban. Juz VII (Cet. I; Beirut: Muassasah al-Risalah, 1408H/1988M), h. 366.

${ }^{42}$ Ahmad bin Ali bin Hajar al-Asqalani, Fath al-Bāri Syarh Sahih al-Bukhari, Juz III (Beirut: Dar al-Ma'rifah, 1379H), h. 186.
} 
itu pula Rasulullah saw. mengumpulkan sahabatnya untuk melaksanakan salat gaib, dan ini menunjukkan bahwa salat gaib hanya boleh dilakukan untuk jenazah yang meninggal hari itu atau yang belum terlalu lama meninggalnya, karena pengurusan dan penyelenggaraan jenazah harus disegerakan.

Jika kita perhatikan semua pendapat di atas beserta dalil-dalilnya, maka tidak ada yang lepas dari kritikan, adapun pendapat pertama yang mengatakan tidak disyariatkannya salat gaib secara mutlak sepeninggal Rasulullah saw. dengan dalil bahwa apa yang dilakukan oleh beliau adalah sebuah kekhususan, hal ini terbantahkan karena tidak adanya dalil yang menunjukkan pengkhususan tersebut, dan syariat yang dilakukan oleh Rasulullah saw. adalah syariat untuk umatnya juga, kecuali ada dalil yang mengkhususkan, dan dalam hal ini tidak ada dalil yang menunjukan kekhususan ataupun yang menghapuskannya.

Adapun pendapat yang mengatakan disyariatkannya salat gaib secara mutlak, hal ini juga terbantahkan dengan banyaknya para sahabat yang meninggal di zaman Rasulullah saw., namun, tidak ada riwayat yang sahih menerangkan bahwa jenazah mereka disalatkan secara gaib oleh Rasulullah saw. dan para sahabat lainnya, sehingga tidak bisa dikatakan bahwa salat gaib disyariatkan secara mutlak.

Begitu pula dengan pendapat yang mengatakan bahwa salat gaib disyariatkan bagi yang berada di arah kiblat, maka hal ini juga tidak bisa diterima karena sebab kebolehan salat gaib, bukan karena berada di arah kiblat, tapi karena hal lain.

Adapun pendapat yang membatasi disyariatkannya salat gaib bagi yang meninggal hari itu dengan alasan bahwa Rasulullah saw. ketika mengetahui kematian Najasyi beliau langsung melaksanakan salat gaib, maka ini juga tidak bisa diterima karena boleh jadi berita kematian seseorang terlambat sampai kepada kaum muslimin.

Adapun pendapat yang mengatakan bahwa salat gaib disyariatkan untuk jenazah yang telah memberikan kontribusi bagi Islam dan kaum muslimin, maka hal ini terbantahkan dengan banyaknya tokoh-tokoh Islam dari kalangan sahabat dan tabiin yang telah memberikan banyak kontribusi terhadap Islam dan kaum muslimin, namun, mereka tidak disalati secara gaib.

Pendapat yang terakhir adalah salat gaib disyariatkan bagi jenazah yang belum disalatkan, karena Najasyi meninggal di daerah musyrik dan belum ada yang mensalatkannya, disebabkan karena beliau menyembunyikan keimanannya dari kaumnya, dan dari telaah peneliti tidak menemukan riwayat yang menyatakan bahwa ada yang menyalati jenazah Najasy di Habasyah. 
BUSTANUL FUQAHA: Jurnal Bidang Hukum Islam

Vol. 1, No. 3 (2020) : Hal. 311-329

Website: https://journal.stiba.ac.id

Setelah melihat dan menimbang pendapat para ulama mengenai salat gaib, maka penulis lebih condong pada pendapat yang mengatakan bahwa salat gaib disyariatkan bagi jenazah yang belum disalatkan.

\section{Tata Cara Salat Gaib}

Telah disebutkan sebelumnya pada pembahasan definisi salat gaib, bahwa salat gaib adalah menyalatkan jenazah yang tidak berada di tempat atau berada di negeri lain. Dengan demikian, dipahami bahwa tata cara salat gaib sama dengan tata cara salat jenazah sebagaimana biasa diselenggarakan oleh kaum muslimin. Yaitu dengan bertakbir sebanyak empat kali; pada takbir yang pertama membaca surah al-Fatihah, yang kedua membaca selawat kepada Rasulullah saw., yang ketiga mendoakan jenazah yang sedang disalatkan, dan yang keempat mengucapkan salam. ${ }^{43}$

\section{Batasan Waktu dan Jarak Dalam Salat Gaib}

Para ulama berbeda pendapat tentang batasan waktu dan jarak dalam pelaksanaan salat gaib, berikut pendapat para ulama dalam batasan waktu beserta dalilnya:

Pendapat pertama. Salat gaib boleh dilaksanakan di hari meninggalnya, sebagaimana yang disebutkan sebelumnya pada pembahasan hukum salat gaib pada pendapat keenam.

Pendapat kedua. Salat gaib boleh dilakukan pada jangka waktu satu bulan saja, sebagaimana salat yang dilakukan untuk jenazah yang sudah dikubur yakni satu bulan. Oleh karena biasanya mayat sudah hancur setelah satu bulan meninggalnya, sebagaimana disebutkan oleh Ibnu Qudamah dalam kitabnya al-Mugni:

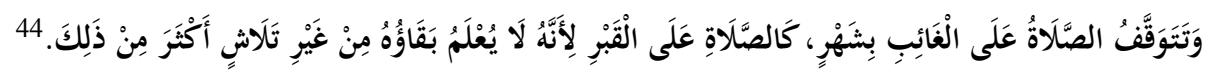

Artinya: "Salat gaib tidak lagi dilaksanakan setelah satu bulan berlalu dari kematiannya, sebagaimana salat mayit di atas kuburan, karena tidak diketahui keutuhannya lebih dari waktu tersebut."

Pendapat ketiga. Salat gaib boleh dilakukan walaupun sudah melewati satu bulan dari kematian jenazah tersebut, hanya saja sebagian ulama membatasi dengan

\footnotetext{
${ }^{43}$ Said bin Ali bin Wahf al-Qahthani, Ahkam al-Janaiz (Riyadh: Muassasah al-Jarisi), h. 247.

${ }^{44}$ Abu Muhammad Muwaffaq al-Din Abdullah bin Ahmad bin Muhammad bin Quddamah, al-Mugni, Juz II (Kairo: Maktabah al-Qahirah, 1388H/1968M), h. 383.
} 
beberapa batasan. Di antaranya adalah si mayit meninggal pada masa orang yang ingin menyalatkannya secara gaib sudah bisa melaksanakan salat, seperti orang yang meninggal dua puluh tahun lalu dan yang akan menyalatkannya saat ini sudah berumur 30 tahun, maka boleh. ${ }^{45}$ Adapun jika yang akan menyalatkannya baru berumur dua puluh tahun atau kurang, maka tidak boleh.

Dari ketiga pendapat di atas, tampak pendapat yang lebih kuat adalah pendapat yang ketiga, oleh karena pendapat yang pertama dan kedua membatasi kebolehan salat gaib atas jenazah seseorang sampai waktu tertentu. Sedangkan kita mengetahui bahwa sebab disyariatkannya salat gaib adalah karena jenazah seseorang belum disalatkan, sehingga selama jenazah tersebut belum disalatkan, maka hukumnya boleh untuk menyalatinya dengan salat gaib dengan ketentuan yang telah disebutkan pada pendapat yang ketiga.

Pembatasan jarak dalam salat gaib juga termasuk hal yang diperbincangkan oleh para ulama, apakah dia dibatasi seperti jarak yang membolehkan qasar salat atau boleh kurang dari itu?. Perbedaan ini disebabkan oleh karena tidak adanya riwayat yang jelas dalam membatasi hal tersebut, sehingga sebagian ulama berpendapat bahwa boleh melaksanakan salat gaib terhadap jenazah yang jauh atau pun dekat, sebagian yang lain mengatakan bahwa jenazah tersebut harus berada di luar daerah yang jaraknya adalah jarak safar, bahkan ada yang membatasi dengan lima puluh langkah. ${ }^{46}$

Dari semua pendapat di atas, penulis lebih memilih pendapat yang membatasi bolehnya dilaksanakan salat gaib jika jarak dari tempat jenazah tersebut berat untuk didatangi, adapun jika jaraknya mudah untuk didatangi, maka tidak boleh melakukan salat gaib terhadap jenazah tersebut.

\section{Hukum Salat Gaib Untuk Korban Bencana Alam}

Kriteria jenazah yang boleh disalati secara gaib adalah semua jenazah yang belum disalati sama sekali, sebagaimana yang telah disebutkan pada pembahasan hukum salat gaib. Akan tetapi, terdapat beberapa kondisi dan keadaan yang perlu untuk dikaji secara khusus, di antara keadaan tersebut adalah jenazah korban bencana alam seperti jasad yang terbakar, tenggelam, hilang setelah tertimpa musibah seperti banjir bandang, tsunami, gempa bumi, likuefaksi dan tanah longsor, atau semisalnya, dan juga jasad seseorang yang dimangsa oleh binatang

\footnotetext{
${ }^{45}$ Muhammad al-Syirbini al-Khatib, al-Iqna’ fii Halli Alfadz Abi Syuja’, Juz I (Beirut: Dār al-Fikr, 1415H), h. 202

46 Taqiyuddin Abul Abbas Ahmad bin Abdul Halim Ibnu Taimiyah, al-Fatā wa al-Kubra, Juz II (Cet. I; Beirut: Dār al-ma'rifah, 1386), h. 533.
} 
buas seperti singa, harimau, buaya dan lainnya. Keadaan-keadaan tersebut telah diperbincangkan oleh para ulama, dan berikut ini adalah ulasan tersebut:

Jasad Yang Terbakar. Jika terjadi sebuah kebakaran yang melanda seorang muslim dan sulit untuk menemukan jasadnya secara utuh, maka wajib untuk disalatkan secara gaib, begitu pula jika hanya sebagian kecil dari badannya yang ditemukan atau bahkan susah untuk membedakannya dengan benda lain, dan tidak memungkinkan untuk dimandikan, dikafani dan dikubur, maka kewajiban penyelenggaraan jenazahnya gugur kecuali salat, maka tetap dilakukan salat gaib untuknya. ${ }^{47}$

Jasad Yang Tenggelam. Jika terjadi sebuah bencana yang menimpa kaum muslimin dan menenggelamkan sebagian dari mereka, apabila jasadnya ditemukan, maka wajib untuk diselenggarakan jenazahnya sebagaimana mestinya, namun jika jasadnya tidak ditemukan maka disalati secara gaib. ${ }^{48}$

Jasad Yang Hilang. Kaum muslimin yang hilang dikarenakan bencana alam seperti tsunami, likuefaksi, tanah longsor, banjir dan yang lainnya, jika memungkinkan untuk dicari dan ditemukan, maka disalati sebagaimana layaknya orang meninggal, namun jika tidak bisa ditemukan karena sudah tertimbun tanah longsor atau terbawa ke laut, atau terjerembab ke dalam tanah, maka disalati secara gaib sebagaimana kondisi yang sebelumnya.

Jasad Yang Dimangsa Oleh Binatang Buas. Jika ada seorang muslim yang dimangsa dan dimakan oleh binatang buas, tidak lepas dari dua keadaan:

Keadaan pertama. Jasadnya dimakan habis oleh binatang tersebut dan tidak bisa lagi ditemukan, maka ulama kita berbeda pendapat dalam hal ini, sebagian mengatakan tidak perlu mensalatinya dan sebagian yang lain berpendapat tetap harus disalati secara gaib. Pendapat yang lebih kuat adalah pendapat yang mengatakan tetap dilaksanakan salat gaib, karena dua hal, yaitu susahnya menemukan jasadnya dalam keadaan utuh, dan salat gaib terhadap jasad tersebut lebih baik daripada tidak sama sekali. ${ }^{49}$

Keadaan kedua. Jasad yang dimakan oleh binatang dan masih tersisa dari jasad tersebut dan bisa ditemukan, seperti orang yang ditelan ular besar dan masih utuh dalam perut ular, atau ada yang tersisa dari bagian tubuhnya yang tidak dimakan

\footnotetext{
${ }^{47}$ Muhammad bin Sholeh al-Utsaimin, Fatawa Arkan al-Islam (Cet. I; Riyadh: Dar al-Tsurayya, 1424H), h. 406.

${ }^{48}$ Muhammad bin Sholeh al-Utsaimin, Fatawa Arkan al-Islam, h. 412.

${ }^{49}$ Muhammad bin Muflih al-Hanbaly, al-Furu', Juz III (Cet. I; Beirut, Muassasah al-Risalah, 1424H/2003M), h. 
BUSTANUL FUQAHA: Jurnal Bidang Hukum Islam

Vol. 1, No. 3 (2020) : Hal. 311-329

Website: https://journal.stiba.ac.id

oleh binatang tersebut, maka keadaan seperti ini, sisa bagian dari jasad tersebut yang disalati dan tidak perlu melaksanakan salat gaib untuknya. ${ }^{50}$

\section{KESIMPULAN}

Para ulama berbeda pendapat mengenai hukum pelaksanaan salat gaib setelah wafatnya Rasulullah saw. Pendapat yang lebih kuat adalah bolehnya salat gaib untuk jenazah yang belum disalati. Tata cara pelaksanaan salat gaib sama dengan pelaksanaan salat jenazah pada umumnya. Oleh karena salat gaib sejatinya adalah salat jenazah, namun perbedaannya adalah karena jenazah yang disalatkan secara gaib tidak berada pada tempat pelaksanaan salat gaib tersebut.

Demikian pula tidak ada batas waktu untuk pelaksanaan salat gaib, namun dipersyaratkan bahwa si mayit meninggal pada masa orang yang ingin menyalatkannya secara gaib sudah bisa melaksanakan salat. Adapun Batas jarak bolehnya salat gaib adalah apabila tempat jenazah sulit untuk didatangi oleh orang yang ingin mensalatinya. Untuk jenazah korban bencana alam, jika tidak ditemukan jasadnya dan belum disalati, maka boleh disalati secara gaib.

\section{DAFTAR PUSTAKA}

Abadi, Muhammad Syamsul Haq al-Adzim. (1415 H). 'Aun al-Ma'bud Syarh Sunan Abi Daud. Cet. II; Beirut, Dār al-Kutub al-Ilmiyah, Juz XI.

Al-Albani, Abu Abdil Rahman Muhammad Nasiruddin. (1986). Ahkam Janaaiz wa Bida'iha Cet. IV; Beirut: al-Maktabah al-Islami.

Al-Albani, Abu Abdil Rahman Muhammad Nasiruddin. (2010). Silsilah AlAhadits Al-Daifah wa Al-Mauduah. Cet. I; Al-Madinah Al-Munawwarah: Maktabah Al-Ulum wa Al-Hikam, h. 438.

Al-Andalusi, Abu Muhammad Ali bin Ahmad bin Hazm. (t.th.). al-Muhallā. Beirut: Dār al-Fikr, Juz V.

Al-Asqalani, Ahmad bin Ali bin Hajar. (1379 H). Fath al-Bāri Syarh Sahih alBukhāri. Beirut: Dār al-Ma'rifah, Juz III.

Al-Baihaqi, Abu Bakar Ahmad bin Husain. (2011). Sunan al-Kubra. Cet. I; Markaz Hajr li al-Buhuts wa al-Dirasat al-Arabiah wa al-Islamiyah, Juz. VII.

Al-Baihaqi, Abu Bakar Ahmad bin Husain. (t.th.). Ma'rifatu al-Sunan wa al-Atsar. Beirut: Dār al-Kutub al-Ilmiyah, Juz I.

${ }^{50}$ Abdul Karim bin Muhammad al-Rafi'iy, Fathul 'Aziz Bisyarhi al-Wajiz, Juz V (Darul Fikri), h. 144. 
BUSTANUL FUQAHA: Jurnal Bidang Hukum Islam

Vol. 1, No. 3 (2020) : Hal. 311-329

Website: https://journal.stiba.ac.id

Al-Bukhari, Muhammad bin Ismail. (1422 H). Sahih al-Bukhari. Cet. I; Dār Tuq an-Najah, Juz II.

Al-Duwaisy, Ahmad bin Abdurrazzaq. (t,th.). Fataawa Lajnah al-Daimah Lilbuhuts al-Ilmiyah Waliftaa'. Cet. al-Riasah al-'ammah lilbuhuts alilmiyah walifta', Juz VIII.

Al-Fairuzabadi, Muhammad bin Ya'kub. (2005). al-Qamus al-Muhith. Cet. VIII; Beirut: Muassasah al-Risalah.

Al-Hanbali, Mansur bin Yunus al-Bahuti. (t.th.). Kassyaf al-Qonna' 'an Matan alIqna’. Dār al-Kutub al-Ilmiyyah, Juz II.

Al-Kalibuli, Abdurrahman bin Muhammad. (1998). Majma' al-Anhar fi Syarhi Multaqa al-Abhar. Beirut. Dār al-Kutub al-Ilmiyyah, Juz I.

Al-Khatib, Muhammad al-Syirbini. (1415 H). al-Iqna’ fii Halli Alfadz Abi Syuja'. Beirut: Dār al-Fikr, Juz I.

Al-Khatthabi, Hamd bin Muhammad bin Ibrahim. (1351 H). Ma'alim Al-Sunan. Cet. I; Halb: Al-Matba'ah Al-'Ilmiyyah, Juz I.

Al-Mardawi, Ali bin Sulaiman. (t.th.). al-Inshaf fii Ma'rifati al-Rajih min al-Khilaf ala Mazhab Imam Ahmad bin Hanbal. Beirut: Dār Ihya al-Turats al-Araby, Juz II.

Al-Nawawi, Yahya bin Syaraf. (1999). al-Majmu’. Beirut: Dār al-Fikr,1997, Juz V.

Al-Qahthani, Said bin Ali bin Wahf. (t.th). Ahkam al-Janaiz (Riyadh: Muassasah al-Jarisi).

Al-Qarrafi, Syihabuddin Ahmad bin Idris. (1994). al-Zakhirah. Cet. I; Beirut: Dār al-Garb Al-Islamy, Juz II.

Al-Rafi'i, Abdul Karim bin Muhammad. (t.th.). Fathul 'Aziz Bisyarhi al-Wajiz. Darul Fikri, Juz V.

Al-Subki, Mahmud Muhammad Khatthab. (1980). al-Din al-Khalis Aw Irsya alKholq Ila Din al-Haq. Cet. III; al-Maktabah al-Mahmudiyyah al-Subkiyyah.

Al-Tamimi, Muhammad bin Hibban bin Ahmad. (1993). Sahih Ibnu Hibban Bitartib Ibnu Bilban. Cet. II; Beirut: Muassasah al-Risalah, Juz VII.

Al-Utsaimin, Muhammad bin Sholeh. (1424 H). Fatawa Arkan al-Islam. Cet. I; Riyadh: Dar al-Tsurayya.

Al-Zahabi, Syamsuddin Abu Abdillah. (2006). Siyar A'lam Nubala'. Mesir: Dār al-Hadis, Juz III.

Al-Zayla'i, Abdullah bin Yusuf. (1357 H). Nashbu al-Rā yah li Ahā dist al-Hidayah. Mesir: Dār al- Hadits, Juz II.

Hajjaj, Muslim. (t.th.). Șahih Muslim. Beirut: Dār Ihya Turaś Arabi, Juz II.

Ibnu Baz, Abdul Aziz. (t.th.).Majmu’ Fatā wa. t.t.; al-Riasah al-'ammah lilbuhuts al-ilmiyah walifta', Juz XIII. 
BUSTANUL FUQAHA: Jurnal Bidang Hukum Islam

Vol. 1, No. 3 (2020) : Hal. 311-329

Website: https://journal.stiba.ac.id

Ibnu Muflih, Ibrahim bin Muhammad bin Abdullah bin Muhammad. (1997). alMubdi' Fii Syarhil Muqni'. Cet. I; Beirut: Dār al-Kutub al-Ilmiyah, Juz I.

Ibnu Muflih, Muhammad. (2003). al-Furu'. Cet. I; Beirut: Muassasah al-Risalah, Juz III.

Ibnu Qoyyim, Muhammad bin Abi Bakar bin Ayyub. (1986). Zād al-Ma'ād fi Hadyi Khairi al-'Ibād. Cet. XIV; Beirut: Muassasah al-Risalah.

Ibnu Quddamah, Abu Muhammad Muwaffaq al-Din Abdullah bin Ahmad bin Muhammad. (1968). al-Mugni. Maktabah al-Qahirah, Juz II.

Ibnu Taimiyyah, Taqiyuddin Abul Abbas Ahmad bin Abdul Halim. (1418 H). alMustadrak 'ala Majmu' al-Fatawa. Cet. I, Juz III.

Ibnu Taimiyyah, Taqiyuddin Abul Abbas Ahmad bin Abdul Halim. (1987). alFatā wa al-Kabir. Cet. I; Beirut: Dār al-kutub al-Ilmiyah, Juz V.

Nata, Abuddin. (2002) Metode Studi Islam. Jakarta: Raja Grafindo Persada

\section{Dari Internet:}

FAJAR.CO.ID. Bahaya! Korban Gempa Palu Diminta Tinggalkan Zona Merah https://fajar.co.id/2019/07/02/bahaya-korban-gempa-palu-diminta-tinggalkanzona-merah/, (Diakses tanggal 27 Juli 2020).

Tribun-Timur.com. Fakta-fakta Terbaru Banjir Bandang Terjang Masamba Lutra, Ini Jalur Alternatif Agar Tidak Terjebak. https://makassar.tribunnews.com/2020/07/14/fakta-fakta-terbaru-banjirbandang-terjang-masamba-lutra-ini-jalur-alternatif-agar-tidakterjebak?page $=1$, (Diakses tanggal 27 Juli 2020). 